\title{
A Animação Sociocultural e a Formação Profissional em Turismo: reflexões sobre a animação turística
}

\section{Sociocultural Animation and Professional Formation in Tourism: reflexions about touristic animation}

\author{
Leonardo Lincoln Leite de Lacerda ${ }^{1}$ \\ Cleide Aparecida Gonçalves de Sousa ${ }^{2}$
}

\begin{abstract}
Resumo
O presente texto traz alguns pontos-chave que são característicos das atuais discussões sobre a Animação Sociocultural, e tem como objetivo contribuir com as reflexões sobre a mesma e também discutir elementos para se observar a experiência turística. A importância dessas idéias reside na necessidade de ampliar os debates sobre a Animação Sociocultural, buscando um repensar sobre a Animação Turística. Para tal intuito, utilizou-se pesquisa bibliográfica tendo como temas centrais a Animação Sociocultural, o Turismo e a Formação Profissional em Turismo. Ao final, espera-se que a proposta de articular a Animação Sociocultural e a Animação Turística não fragmente a Animação Sociocultural, mas sim incentive outros campos do saber a fornecer mais subsídios para a configuração da própria.
\end{abstract}

Palavras-chave: animação sociocultural; turismo; animação turística; formação profissional.

\begin{abstract}
The present text brings some key points that are characteristics of the current discussions on Sociocultural Animation. It also approaches aspects referring to the field of tourism and it has the pretension of contributing to the reflections on it and simultaneously bringing new elements to observe the tourist experience. The importance of these ideas lies on the need of broadening the debates on Sociocultural Animation and on the possibility of showing the Tourist Animation as a relevant construct to reflections/ intervention. A bibliographical research centered on Sociocultural Animation and Tourism was used as means to this end. At the end, we hope that the proposal of establishing a narrower relation between the two animations does not stimulate the fragmentation of Sociocultural. On the contrary, we hope it will stimulate other fields of knowledge to contribute to the configuration of Sociocultural Animation.
\end{abstract}

Keywords: sociocultural animation; tourism; tourist animation; professional formation.

\footnotetext{
${ }^{1}$ Mestre e Especialista em Lazer pela UFMG. Graduado em Turismo pelo Centro Universitário Newton Paiva. Email: leollacerda@yahoo.com.br

${ }^{2}$ Mestre e Especialista em Lazer pela UFMG. Graduada em Turismo pelo Centro Universitário Newton Paiva. E-mail: cleide_tutora@yahoo.com.br
} 


\section{Introdução}

Não é tarefa simples iniciar um texto sobre Animação Sociocultural. Os principais motivos estão ligados ao fato do citado termo ser novo, além de não ser recorrente no meio acadêmico e no mercado de trabalho. Por ser um campo de estudos atual, são escassos, ainda, os eventos acadêmicos que abordam tal assunto, acarretando um reduzido número de materiais didáticos e discursivos sobre Animação Sociocultural. Além disso, quando se começa a aprofundar nos estudos da Animação Sociocultural, percebe-se as inúmeras relações que se estabelecem e os infindáveis cuidados que se deve tomar ao lidar com a mesma. Por outro lado, essas mesmas dificuldades servem como fator incentivador para se debruçar sobre o assunto, pois muito ainda está por ser escrito e desenvolvido.

Para concretizar os objetivos deste documento, que são contribuir com a construção dos pensamentos sobre a Animação Sociocultural e trazer novos elementos para se observar a experiência turística, inclusive em termos de formação e atuação profissional da área, realizou-se uma pesquisa bibliográfica tendo como temas centrais a Animação Sociocultural, o Turismo e a Formação Profissional em Turismo. A pertinência de realizar esta reflexão reside na necessidade de ampliar os debates referentes ao processo de animação, incluindo o turismo como uma possibilidade de intervenção.

Nesse sentido, o texto aborda inicialmente a Animação Sociocultural, fornecendo fundamento para discussão posterior com o turismo, numa perspectiva da Animação Turística. Mais adiante a Animação Sociocultural é contemplada numa discussão com o campo de estudo do turismo, sendo encerrada com reflexões finais.

\section{Animação Sociocultural}

Melo (2006) revela que a Animação Sociocultural se sustenta em três pilares: o caráter cultural, a dimensão social e a esfera educativa. Segundo o autor, o primeiro pilar muda de acordo com a situação histórica e que atualmente é entendida como um conjunto de normas e valores que "guiam" as pessoas e suas relações, normas e valores que costumam valorizar determinados tipos de manifestações, notadamente as ligadas às artes. Assim e de forma geral, a cultura acaba sendo vista como um fator de distinção social, sendo poucos aqueles que podem acessar determinadas manifestações. 
Gomes e Faria (2005), com apoio em autores como Geertz (1979) $)^{3}$ e Hall (1997) $)^{4}$ tentam analisar a cultura em termos simbólicos, observando-a como elemento central na vida das pessoas, atribuindo significados e dando sentido às práticas exercidas. As coisas, assim, girariam em torno de um "consenso" estabelecido entre um grupo, gerando percepções similares sobre o mundo; o que não impede que resistências e diferentes formas de pensar apareçam. E devido a essa rede de tensões e contradições que Alves $(2004$, p. 56) escreve que “A cultura é o ser humano, é o que há mais de humano no ser, é aquilo que nos distingue dos outros animais".

A animação sociocultural pauta-se no princípio de que todos são consumidores e produtores de cultura, por isso seu foco é na democratização. Destacadas tais características, não seria interessante a imposição de conceitos e princípios, e sim o diálogo. A idéia não é a "elitização" das ações, ou seja, alguns, no caso os animadores, decidindo o que será difundido; nem de substituição, que pressupõe uma escala de valores culturais na qual as escolhas das pessoas devem ser permutadas pelo que os animadores decidirem. Não é função da Animação Sociocultural usar elementos da arte e da cultura para ensinar valores, e sim educar para a arte e a cultura.

Pelo processo de democratização e diálogo chega-se ao pilar "social", que diz respeito à atuação na vida comunitária. Essa visão de trabalhar com apenas um "determinado grupo" se pauta na preocupação de entendê-lo em suas particularidades e ajudá-lo a adotar uma postura participativa nas decisões e nas ações desenvolvidas. Por isso, autores como Ventosa (2007) falam que a atuação da Animação Sociocultural só é possível no âmbito micro social, ou seja, em bairros, em associações, por exemplo. Reforça-se a idéia de que as atuações devem ser elaboradas e desenvolvidas com a população local, e não exercida de maneira unilateral, ou seja, para a comunidade.

No terceiro pilar, a educação, são observáveis três esferas: a educação formal, a não formal e a informal. A primeira se dá de forma sistematizada por instituições como escolas e universidades. A não formal é aquela que possui uma intencionalidade para agir em questões educacionais, não se limitando a determinados espaços como os citados anteriormente. Já a informal é a que compreende a família, a igreja e a comunidade, vendo-os como agentes educativos, mas que não apresentam uma intervenção educativa sistematizada (ALVES et. al.

\footnotetext{
${ }^{3}$ GEERTZ, Clifford. 1979. Interpretação de culturas. Rio de Janeiro: Zahar.

${ }^{4}$ HALL, Stuart. 1997. A centralidade da cultura: notas sobre as revoluções culturais de nosso tempo. Educação e Realidade, 22 (2), p. 15-46.
} 
2005). E apesar de Lopes (2007) indicar que a Animação Sociocultural só se desenvolveria na educação não formal, é possível observar que outras possibilidades, podendo se concretizar dentro do espaço escolar e instituições diversas como a igreja, associações de bairro, entre outras.

Diante dessas três pilastras, Lopes vê a Animação Sociocultural como uma "acção com dimensão social cultural e educativa que tenha por objectivo dinamizar programas junto das populações" (2007, p. 1). Entretanto, a Animação Sociocultural é complexa, envolvendo questões delicadas que não se encontram claras na definição. Portanto, antes de trazer outra concepção, torna-se primordial discutir sobre alguns pontos relevantes para uma reflexão cuidadosa.

Na Animação Sociocultural, os programas que são desenvolvidos junto com a população não podem se restringir apenas ao oferecimento de produtos, seja um bem, serviço, idéia ou pessoa. É preciso que os animadores ajudem os sujeitos a "lerem" os diferentes tipos de manifestações culturais, intervenção que Melo (2006) chama de "alfabetização cultural”.

A democratização das diversas linguagens funciona como ampliação de possibilidades de prazer que podem ser fruídas nas inúmeras manifestações da cultura popular, erudita, e não apenas na cultura de massas. Essa possibilidade é permitida via educação estética, ou seja, a educação dos sentidos, despertando para outros valores estéticos não conhecidos, aumentando o prisma de escolha do cidadão, seu senso crítico e conseqüentemente a emancipação em relação às imposições culturais. Isso pode auxiliar as pessoas a ampliarem suas opções nos momentos de lazer, por exemplo. Lembrando que não se trata de um ato simples de realizar, torna-se necessário que o animador tenha uma formação muito eclética e flexível para este tipo de intervenção, inclusive no que se refere à ampliação de suas próprias vivências.

Um ponto marcante da Animação Sociocultural é a luta por uma comunidade mais consciente, que reflita sobre o que é produzido e sobre o que está sendo acessado, incluindo as propostas dos próprios animadores. Algo que deve ser visto com preocupação, pois não existe interlocutor neutro. Cada pessoa carrega intencionalidades em suas intervenções e, mesmo que o fito seja ajudar a solucionar os problemas de um determinado grupo, nem sempre tal atitude estará em consonância com as necessidades e desejos da comunidade.

A reflexão e o fortalecimento dos vínculos grupais são caminhos indispensáveis para que os sujeitos se sintam mais livres para tomarem suas decisões, mais cientes das opções que se apresentam. As pessoas a quem se destina a atuação dos animadores são vistas como sujeitos 
ativos do processo e são incluídas no planejamento e desenvolvimento das atividades. O objetivo do animador sociocultural é fortalecer os indivíduos criticamente e dessa maneira fortalecer o grupo. Sua intervenção não é ortodoxa, pois às vezes se pretende "desorganizar" as idéias vigentes e fazer com que o grupo repense sua postura e suas "verdades". Tudo isso para alcançar uma construção social mais justa que "somente pode se dar quando tivermos individuos fortes e ativos, sujeitos que possam se expressar e se posicionar de maneira clara e explícita" (MELO, 2006, p. 65).

A Animação Sociocultural age pela mediação, ou seja, ação pela comunicação, zelando para que os meios de conversação sejam de mão dupla: tanto para a comunidade quanto para o animador. Importante ressaltar que a partir dessa mediação novas perspectivas poderão surgir, alterando as necessidades e desejos da comunidade e as expectativas dos animadores. A mudança, assim, é um fator presente na Animação Sociocultural, numa tentativa de sempre mostrar alternativas.

De forma sintética, Lopes (2007, p. 11-12) observa que "Animar constituirá agora e sempre um acto de comunicação, de interacção e promoção da vivência a partir da convivência, da acção com reflexão, e isto comporta formas inovadoras nos planos social, cultural, educativo e político". Entretanto, a mudança muitas vezes não é bem aceita pelas pessoas, pois permanecer na conformidade traz uma sensação de segurança. Por tanto, o animador sociocultural deverá caminhar com cuidado, devendo se preparar para as infindáveis possibilidades de contra posturas por parte da comunidade.

$\mathrm{O}$ ato de incomodar faz parte da Animação Sociocultural, uma vez que leva ao estímulo do pensamento e possibilita a descoberta de novas belezas. E para conseguir alcançar tantos objetivos, o animador sociocultural deverá utilizar distintas formas de trabalho, tanto no nível racional (instrumentos, técnicas, reflexões) quanto no nível estético (emoções, sensações, prazer).

Por esse emaranhado de imbricações que compõe a Animação Sociocultural, convém adotar aqui um conceito que tenta englobar todos os matizes que envolvem o termo. Assim, para Melo (2006, p. 28-29), a Animação Sociocultural é:

(...) uma tecnologia educacional (uma proposta de intervenção pedagógica) pautada na idéia radical de mediação (que nunca deve significar imposição), que busca permitir compreensões mais aprofundadas acerca dos sentidos e significados culturais (considerando as tensões que nesse âmbito se estabelecem) que concedem concretude à nossa experiência cotidiana, construída com base no princípio de 
estímulo às organizações comunitárias (que pressupõe a idéia de indivíduos fortes para que tenhamos realmente uma construção democrática), sempre tendo em vista provocar questionamentos acerca da ordem social estabelecida e contribuir para a superação do status quo e para a construção de uma sociedade mais justa.

Como lembra o autor, é preciso também que o animador entenda como a ordem social está estabelecida e como influencia as pessoas. Esta preocupação deve fazer parte do planejamento das ações dos animadores e da comunidade, evitando repetir injustiças comumente observáveis no cotidiano.

Embora o autor citado acima traga contribuições para a compreensão desta tecnologia educacional, é de sua preferência a utilização do termo Animação Sociocultural, priorizando a interferência no campo da cultura. Entretanto, este texto optou por aderir ao clássico termo “Animação Sociocultural”, pois se trata de um termo mais amplo e capaz de apresentar melhor a proposta da intervenção.

Importante frisar que apesar de apresentar tantas características positivas, a Animação Sociocultural não se configura como um remédio para todos os males, e nem pretende ser. Essa tecnologia educacional é um instrumento para ajudar os sujeitos a alterarem o rumo que a sociedade vai seguindo, mostrando que sempre existem opções para o que está posto ou imposto.

Outro ponto relevante a se destacar é lembrar que mesmo que as pessoas sejam auxiliadas a ler os diferentes tipos de manifestações, contribuindo para o seu fortalecimento, as ações da animação sociocultural podem não garantir a geração de um sujeito consciente, ativo e disposto a colaborar para a construção de uma nova sociedade. Contudo, isso não impede que o animador continue se esforçando para alterar o status quo. E no intuito de reforçar a necessidade de lutar por um mundo melhor é sempre recomendável reunir esforços e trocar idéias com campos afins, especialmente porque a Animação Sociocultural não se restringe a uma determinada área. E o turismo é um dos campos de estudo que podem colaborar para a discussão.

\section{O Turismo e a Animação Turística}

De acordo com Lopes (2007), a Animação Sociocultural comporta uma pluralidade de âmbitos concernentes a diversas áreas temáticas, sendo o turismo uma delas. Desse ponto surge o termo Animação Turística como um possível vínculo entre ambos os campos. 
Entretanto, apesar do mesmo autor apontar que este tipo de intervenção - assim como a Animação Teatral, a Animação Socioeducativa e a Animação na infância, nos adultos e terceira idade - já se encontra consagrada, observa-se a escassez de estudos acadêmicos sobre o tema.

Uma possível explicação para tal fato pode estar atrelada à regularidade da utilização da palavra "turismo", a qual, pelo auxílio da evolução tecnológica que diminuiu distâncias com instrumentos de transporte (carros, trens, aviões, navios...), e com a inovação no campo das comunicações (Internet, televisão...), tornou-se uma atividade socioeconômica de grande repercussão nas últimas décadas. Apesar de que, como aponta Burns (2002), é preciso desconfiar desses números que giram em torno do turismo, pois são cercados pela ausência de definições de consenso internacional.

Ainda que houvesse referências amiúde sobre a Animação Turística no contexto europeu, seria preciso investir em estudos em outras regiões, como a América Latina, visto que as realidades são diferenciadas. Por exemplo, enquanto no estudo de Lopes (2007), de vínculo é europeu, é abordado que o animador deve se engajar no combate ao absenteísmo, sabe-se que no Brasil a atuação costuma focar os direitos sociais, uma vez que os mesmos não foram totalmente atendidos.

O mesmo autor afirma também que não defende um termo "guarda-chuva", o qual seria capaz de abrigar os demais (Animação Teatral, Animação em Museus, Animação Sociolaboral, etc). Idéia interessante, mas é preciso zelar para que ela não leve à formação de novas teorias para os variados âmbitos da animação, o que poderia gerar um enfraquecimento da própria Animação Sociocultural. Dessa forma é possível, e quiçá recomendável, que exista um vocábulo central para as diferentes propostas de animação, tendo, por exemplo, o cerne da Animação Sociocultural como base para as intervenções da Animação Turística; tomando os devidos cuidados para observar as suas especificidades.

É possível considerar o turismo atualmente sob sua dimensão sociocultural global. E por isso, em grande parte, estabelecem-se relações com a Indústria Cultural, culminando na utilização do termo "Indústria Turística". Aqui, é costume ocorrer vivências concebidas por quem oferece o produto, negligenciando os sujeitos que as experimentam. Como aborda Santos Filho (2005), essa é uma realidade constante no universo do turismo, visto que o seu desenvolvimento se deve ao sistema capitalista, que visa a aquisição de capital para os detentores dos meios de produção. 
Ao agir sem considerar as aspirações e peculiaridades do turista e esforçar para que o mesmo tenha consciência do pacote adquirido, ressalta-se a conformidade, ou seja, a aquisição de bens e serviços uniformes. Lembrando que o interesse que costuma prevalecer é um turismo como forma de recuperar as forças para o trabalho como maneira de fugir dos problemas cotidianos, fatores que alimentam o status quo.

Mesmo em uma sociedade do consumo como a que se apresenta, é possível encontrar alternativas. Ao dizer isto, não se pretende negar ou repudiar as vivências da Indústria Cultural, até mesmo porque, em grande parte, elas são uma presença constante nas relações estabelecidas e também porque trazem experiências significativas para quem as experimenta. É preciso superar o preconceito que geralmente existe ao se analisar um determinado tipo de manifestação, como aponta Pereira (2006, p. 363):

As manifestações culturais não devem sofrer restrições a priori ou preconceitos, mas serem encaradas como processo de conflito e tensão inerentes às relações sociais, posicionando-se assim de forma ativa e crítica, evitando, por um lado, os pré-juízos característicos de uma inclinação mais extremista, e, por outro, uma atitude de passividade, como se as relações sociais fossem dadas e naturais e não construções históricas.

Sem o intuito de excluir os produtos formatados pela Indústria Cultural, é possível mostrar que existem diferentes e interessantes formas de se estabelecer uma relação com o turismo, na qual a participação do turista seja mais ativa e consciente.

Outrossim, outra possibilidade é ressignificar o turismo, que atualmente está impregnado por valores economicistas, como revela Santos Filho (2005, p. 38):

A noção que ganha campo nas políticas públicas e turismo é aquela que privilegia a vinda do turista estrangeiro, ou seja, que vende o Brasil par ao fluxo internacional. Esse pensamento cabotino e delirante dos neoliberais entende o turismo como pura venda de mercadoria, esquecendo os benefícios de uma política voltada para o turismo interno.

Ao incrementar o lado social, pode-se analisar o turismo como um elemento que pode enriquecer o indivíduo ao postá-lo frente a situações novas, instigando-o a refletir sobre sua própria cultura, ajudando-o no seu desenvolvimento pessoal. Como afirma Higuchi (2003, p. 203), é "no contato com outras pessoas que as personalidades se desenvolvem, na ação e reação que provocam". 
Seguindo essa linha de pensamento para o Turismo, poder-se-ia arriscar a propor uma Animação Turística voltada para o próprio local em que se reside, o que confrontaria a idéia de que para se fazer turismo é necessário grandes gastos financeiros e um deslocamento distante do entorno habitual. Esta intervenção pautada no ideal de Animação Sociocultural poderia se mostrar vantajosa ao situar as pessoas não apenas como transeuntes em sua própria cidade, mas sim como sujeitos participativos de sua própria cidadania, contando, neste caso, com uma educação para o tempo livre.

Entendendo a essência do turismo como o contato com o novo e visualizando os grandes centros urbanos como repletos de espaços a serem desvendados, seria possível desenvolver esta experiência na cidade a qual as pessoas habitam (LACERDA, 2007). E a Animação Turística - não pautada aqui na simples promoção/ reprodução de atividades, mas sim no estímulo à emoção com o espaço visitado - poderia colaborar com o conhecimento mais aprofundado e significativo das pessoas com seu próprio lugar, vendo e revendo sua história e dando um sentido de pertencimento ao morador. A Animação Turística, assim, estaria em certo sentido empenhada em ajudar o sujeito a exercer a cidadania, pois o auxiliaria a retomar os espaços públicos, tão vazios nesses tempos de exacerbação da violência. E reforçando a idéia de que as relações concretizadas nos meios públicos (ou meios sociais) são importantes para a educação cidadã, França $(2005$, p. 21) afirma que:

(...) o meio social é fator determinante na visão ampliada de educação [...] para promover os indivíduos de conhecimento e experiências culturais dotando o ser para atuar socialmente sintonizado criticamente em relação às situações do cotidiano em dimensões ancoradas no sentido e no significado da diversidade e da coletividade.

Krippendorf (2001, p. 162-163) faz pensar sobre essa relação com o turismo quando relata que devemos "aprender a ver claramente dentro de nós para podermos olhar com lucidez para o mundo exterior". O contato com as manifestações histórico-político-sociais de onde um sujeito reside é o "olhar para dentro", aprendendo assim a observar para fora (outras cidades, estados regiões e países). Dentro desse tipo de intervenção, os sujeitos que experimentariam este tipo de turismo poderiam reconstruir a visão que costuma imperar: a de supervalorizar certas culturas - notadamente a capitalista, européia, branca, e cristã (ALVES 2004) - em detrimento de outras. Então, trabalhar pelo turismo com os moradores tendo como cenário sua própria cidade seria um tipo de intervenção da Animação Turística. 
O que se pode pensar a princípio quando se pretende realizar este tipo de ação é que se está trabalhando para alcançar uma visão idealizada pelo animador sociocultural, o que nem sempre ocorre. Entretanto, também não se trabalharia unicamente para o que o público deseja. O que se deseja é a conseqüência do que é discutido nos encontros e conversas do animador com a comunidade, chegando-se a um terceiro olhar que enriquece tanto o primeiro quanto o último. É o que destaca Melo (2006, p. 64) ao dizer que:

O processo de animação cultural não é o que o animador quer, não é o que o público quer, mas sim as reelaborações constantes baseadas no estímulo que o animador possibilita no público e no estímulo que o público ocasiona no animador, sem nenhuma pretensão de enquadramento.

Sendo assim, a Animação Turística poderia almejar opções tendo um contato diferente não só com os turistas, mas também com os sujeitos residentes de uma dada localidade turística. Esses moradores ou autóctones também representam uma parte significativa da Animação Turística, devendo ser levados em consideração nesse processo. Tal preocupação com o morador local se justifica pelo fato de o turismo ainda estar em profunda sintonia com os interesses econômicos, fazendo com que o foco se volte para aqueles que detêm os recursos financeiros: os turistas. E nessa direção, agravam-se complicadores na relação morador-turista, como: a) a transitoriedade do contato, marcada pela superficialidade, b) limitações espaçotemporais, quando de um lado existe o interesse em querer ser servido na "hora certa" e do "jeito certo" e do outro lado existir a pretensão de vender tudo que for possível, c) falta de espontaneidade devido à padronização dos serviços e d) desigualdades materiais e comportamentais, que geram uma aparente hierarquia social (SEVERINO et. al., 2006).

Trabalhar com os moradores de destinos turísticos exige ações mais estratégicas, pois geralmente estes não recebem um retorno positivo (recursos financeiros, preservação da localidade, entre outros) da atividade turística.

Gastal e Moesch apresentam uma idéia ao aproximar estes dois públicos:

(...) é fundamental que aqueles que viajam saibam viajar, afetando ao mínimo os espaços percorridos. Também é fundamental que os que recebem visitantes saibam receber; não com subserviência, advinda da força econômica que a atividade turística pode exercer, mas com orgulho de quem sabe quem é e conhece os papéis a desempenhar numa comunidade hospitaleira. (2007, p. 10) 
E nesse desempenho de papéis é relevante se preocupar com o patrimônio natural e cultural existente nas cidades, fato que não implica somente os bens materiais. Inserem-se aí as riquezas folclóricas e religiosas (a dança, a música, a culinária, o jeito diferenciado de andar, de conversar e de tocar um sino). Trabalhar nessa direção é importante, visto que Gillet (2006) percebe que um determinado grupo costuma se destacar na história por intermédio do domínio cultural, meio que define a identidade e fornece visibilidade a um povo e a um espaço social. Contudo, há de se ponderar ainda sobre o assunto, não achando que todas estas manifestações devem se transformar em atrativos turísticos. Se a Animação Turística está sendo baseada nos princípios da Animação Sociocultural é preciso fazer valer - dar voz a - os interesses dos moradores, levando-os a se conscientizar das vantagens e desvantagens de cada escolha antes de seguir adiante com as ações.

Para assumir toda essa complexidade, valeria pensar em um processo de Animação Turística voltado para os próprios funcionários do setor turístico. Uma vertente que seria interessante trabalhar aqui é a de buscar a troca de idéias desses profissionais com os dois outros públicos: os turistas e os autóctones. A mediação, dessa forma, seria um conhecimento indispensável para tais profissionais, já que estes estariam intermediando os interesses e expectativas dos dois públicos.

Cada vez mais os estudos sobre a mediação estão sendo valorizados, uma vez que o tema "diversidade cultural" vem galgando patamares de interesse, sendo presente na fala de diferentes autores e também exposto em variadas disciplinas do campo do conhecimento (GOMES e FARIA 2005). Entretanto, antes de abordar essa vertente, cabe fazer uma reflexão sobre o mercado de trabalho do setor de turismo. Devido à sua diversidade, seria inapropriado lidar com todos os seus ramos. Portanto, para facilitar a leitura, optou-se por debater o caso dos hotéis de lazer, que costumam apresentar exemplos de ações pertinentes à discussão no tratar o hóspede.

\section{O Contexto dos Hotéis de Lazer}

Para aprofundar as reflexões sobre a Animação Turística e Animação Sociocultural, parece relevante pensar o espaço onde tais práticas se materializam, como os hotéis de lazer: quais conteúdos estão sendo implementados nesses espaços? Qual a sua a lógica de organização?

Tais equipamentos podem ser entendidos como estabelecimentos direcionados não apenas para estada, mas para recreação ou entretenimento dos hóspedes. Esse direcionamento é 
observado em suas instalações, tanto nos aspectos arquitetônicos, de engenharia, de equipamentos, quanto nos serviços oferecidos. Dessa maneira, pode-se compreender que esses estabelecimentos deveriam contar com um programa de animação e profissionais específicos da área para que toda estrutura seja aproveitada.

Marcellino $^{5}$, (citado por STOPPA e ISAYAMA, 2001, p 76), aponta que é recorrente observar duas correntes para atuação desses profissionais: a) trata o lazer como mercadoria - um pacote fechado, pronto, com o objetivo apenas de distrair as pessoas; b) considera o lazer como uma construção histórica e social, entendendo-o como uma possibilidade de desenvolvimento de "valores questionadores da ordem estabelecida e colaborando com a formação de indivíduos críticos e participantes da sociedade".

O que se tem observado nos hotéis desse ramo, de maneira mais comum, é a visão do lazer de acordo com a primeira corrente. Atuação à qual se dá o nome geralmente de "Animação Turística", mergulhada em uma visão tradicionalista, na qual os animadores, sob insistência dos gerentes, limitam-se a oferecer aos hóspedes uma programação. Essa postura acaba retirando do hóspede a possibilidade de escolher a contemplação, ou simplesmente de fazer o que se tem vontade.

O uso dos conceitos "recreação" e "entretenimento" nesses hotéis fornece pistas da filosofia de trabalho que norteia a atuação profissional nessas instituições, voltados para o simples oferecimento de atividades como forma de passar o tempo.

Apesar de Torres (2004, p. 3) defender um conceito humanizador para a Animação Turística, ou seja, um "[...] conjunto de programas elaboradas com finalidade de humanizar uma viagem, fazendo com que o Turista se integre nela e participe ativamente", a autora traz em suas idéias elementos que reforçam o divertimento como meio de descontração e de fuga dos problemas cotidianos. Além do mais, a preocupação econômica (animar os turistas para prolongar a sua estada e gerar mais receita para o empreendimento) parece suplantar o aspecto sociocultural.

Nesse sentido, o hóspede se torna um sujeito passivo, tendo contato apenas com o produto final, com a atividade formatada, não sendo o sujeito tratado como participante da programação, do planejamento das atividades. Muitas vezes não tem nem mesmo a oportunidade de sugerir, questionar, criticar, opinar sobre tal processo.

\footnotetext{
5 MARCELLINO, Nelson C. 2001. Políticas de Lazer: Mercadores ou Educadores? Os Cínicos Bobos da Corte. In: MARCELlINO, Nelson C. (org). Lazer e Esporte: Políticas Públicas. Campinas: Autores Associados.
} 
Ribeiro (2004, p. 94) coaduna com essas percepções e acrescenta que:

Os gerentes/proprietários dos hotéis acreditam que somente participando efetivamente das atividades de lazer dirigidas é que os hóspedes irão retornar e recomendar o hotel a outras pessoas. Assim, passam a sondar e pressionar os animadores para que estes levem os hóspedes a participar de toda a programação de lazer oferecida.

Há certo amadorismo nesse segmento turístico, no sentido da crença de que não exista uma necessidade de formação profissional aprofundada para se trabalhar no turismo e no lazer. Porém, ultimamente há perspectivas de mudanças desse quadro com o crescimento e a valorização da atividade e o aumento do número de instituições superiores que oferecem formação nas áreas.

Ainda assim, há uma visão deturpada de como deve ser a atuação desse profissional, segundo a qual Marcellino (2000) relata situações em que o profissional no segmento do lazer se submete a funções constrangedoras para chamar a atenção e garantir a diversão dos hóspedes, transformando-se na própria atividade. $\mathrm{O}$ mesmo autor alerta para a ocorrência da venda da personalidade por parte desses profissionais, que chegam até a afirmar que o bom humor seria mais fundamental que a competência e que para tanto o profissional deve ter alegria, carisma e fazer as pessoas rirem.

Sob essa observação, pode-se fazer uma idéia do perfil do profissional que se costuma valorizar: a pessoa alegre, extrovertida, sempre sorridente e agradável mesmo diante de situações difíceis ou constrangedoras, trabalhando e insistindo incansavelmente para que o hóspede participe das atividades programadas.

Os animadores [...] preocupados em receber uma boa avaliação de seus patrões, não só direcionam a programação, mas convidam os hóspedes de forma tão insistente e constrangedora que estes acabam participando muito mais por obrigação do que por vontade própria. (RIBEIRO, 2002, p. 96).

Essa forma de atuação dos animadores turísticos acaba tendo uma dupla dimensão de desrespeito. Uma para com os turistas e outra para com sua própria formação profissional, que acabam tendo de agir sob pressão dos proprietários e gerentes do estabelecimento do que pelo que acredita ser mais válido. 
Observando esse tipo de contexto, Souza e Silva (2008) prefere abordar a Animação Turística como um possível potencializador e promotor de um turismo estimulativo, que reforce a participação crítica durante a descoberta dos locais visitados. Um turismo que consiga interligar as pessoas (moradores e turistas) e fazê-los interagir com o meio, preocupação voltada mais para o envolver do que para o ver. Preocupação também levantada por Araújo (2007, p. 459) quando afirma que "os turistas simplesmente passam pelos trajetos escolhidos sem vivenciá-los, desencadeando uma série de relações culturais superficiais que se resumem no contato com os funcionários de uma pousada ou de um restaurante localizados ao longo das estradas."

Refletir sobre a organização comunitária como um eixo fundamental da Animação Turística pode levantar alternativas à realidade observada, mas como lidar com esse aspecto se no hotel de lazer pressupõe-se a presença de um grupo de desconhecidos?

A princípio não haveria vínculos possíveis ou tempo suficiente para que tais conexões fossem criadas, mas é possível pensar em aspectos que reúnam tal grupo. Pode-se pensar na fomentação da autonomia do grupo como participante ativo da programação das atividades, ou intervenções e sugestões no espaço ou serviço oferecido.

Importante deixar claro nesse processo que uma "mobilização social" pode não ser possível promover nesses espaços, devido ao curto período de tempo em que os hóspedes convivem. Contudo, a intervenção do profissional de posse dos fundamentos da Animação Sociocultural pode fazer com que a participação dos turistas seja repensada através de vivências nos momentos de lazer. Um trabalho educativo pode sensibilizar esse sujeito sobre questões políticas, artísticas, de educação ambiental no espaço visitado, e quiçá ampliar essa perspectiva para o seu lugar de origem.

Apesar de os estudos sobre lazer e turismo cada vez se apresentarem mais desenvolvidos em nível acadêmico, ainda há uma tendência no mercado de medir a competência desse profissional pela sua capacidade de fazer uma pessoa rir, sem levar em conta o que realmente interessa ao hóspede.

Olvida-se que os profissionais desses campos visam o bem-estar, estado gerado pelas situações em que as pessoas tenham o direito de agir naturalmente. Portanto, o profissional tem que estar "à vontade" com o que faz. Não sorrir em tempo integral não significa estado de insatisfação, ou que desempenha sua função sem dedicação. Confrontar esses preceitos arraigados nos hotéis de lazer, assim como em outros equipamentos turísticos, pode ser um 
desafio interessante para a Animação Sociocultural, uma vez que desencadeia novas percepções sobre a realidade. Além desses espaços, repensar a Animação Turística envolve refletir sobre o meio acadêmico, como discutido a seguir.

\section{A Animação Sociocultural como Conteúdo Curricular no Turismo}

Além dos turistas, dos autóctones e dos funcionários do setor turístico, outro tipo de público que pode se encontrar no processo de Animação Turística é o docente de cursos de formação em turismo, em seus diferentes níveis: técnico, de graduação e de pós-graduação. Estes formadores ${ }^{6}$ também podem desempenhar um papel importante no turismo tendo como base os preceitos da Animação Sociocultural.

Entretanto nem todos aqueles que se formam nesses cursos estarão aptos ou desejarão atuar nessa vertente, ainda mais em uma realidade como a brasileira que constituiu os cursos de turismo voltados para os interesses de mercado. Situação arraigada ao turismo, fazendo-o aparecer na Constituição Brasileira de 1988 no Título VII (Da Ordem Econômica e Financeira), no Capítulo I (Dos Princípios Gerais da Atividade Econômica) e no Artigo 180 da seguinte maneira: “A União, os Estados, o Distrito federal e os Municípios promoverão e incentivarão o turismo como fator de desenvolvimento social e econômico" (1988, p. 123). Apesar de aparecer o desenvolvimento social no artigo, o enfoque que se volta ao fator econômico.

Alguns estudos ${ }^{7}$ mostram que a criação dos cursos de graduação de turismo no Brasil (a maioria de instituições privadas) só se consolidou porque havia um interesse em disponibilizar mão-de-obra para um mercado em ascendência. Por toda essa carga histórica, as disciplinas desses cursos se configuraram mais com uma parte prática, negligenciando o lado teórico, tanto também porque no início não havia muitas referências.

Muitas das disciplinas atuais ainda mantêm essa característica técnica, notadamente as relacionadas à esfera do lazer. Algumas disciplinas intituladas Animação Turística trabalham mais com práticas recreativas, e em grande parte voltadas para os meios de hospedagem, fato que reduz as potencialidades do termo.

\footnotetext{
${ }^{6}$ Para esclarecimento, esse público também é visto como pertencente à categoria de profissionais de turismo, mas devido ao senso comum não observá-lo inserido no mercado de trabalho do setor, acabam sendo colocados à parte.

${ }^{7}$ Como de Matias (2002) e de Santos Filho (2006).
} 
Considerando-se que o turismo é uma área multidisciplinar, por que não diversificar a forma de pensamento desses cursos? A Animação Sociocultural poderia auxiliar nesse sentido, inquietando o corpo discente, docente e a parte administrativa dos cursos e estimulando-os a formularem novas visões, resistindo à tendência quase unilateral da economia.

Os alunos, além de se empenharem em desenvolver técnicas como de interpretação do patrimônio cultural, poderiam ser estimulados a refletir sobre o contexto em geral. Como Ander-Egg (2006) discorre, seria importante, por exemplo, perceber que o simples incremento do bem-estar material não significa necessariamente um enriquecimento cultural. Assim sendo, o animador na perspectiva turística não deve se fixar apenas no domínio da técnica, mas também em como aplicá-la. Postura também defendida por Ventosa (2007, p. 10, tradução nossa) ao colocar que o animador sociocultural não é definido pelo que faz, mas sim como faz, e acrescenta que a função do animador pode ser resumida da seguinte forma: "Fazer algo que dê sentido à vida de um grupo".

Estruturar apenas uma disciplina nos cursos de turismo nos moldes da Animação Sociocultural não é suficiente para uma contribuição significativa para se formar um animador. Essa visão de que o currículo é composto por uma quantidade organizada de disciplinas ao longo do curso é fruto de uma concepção tradicional. As teorias críticas e póscríticas sobre currículo, de acordo com Silva (2005), levantaram a percepção da existência de várias questões, às quais estão relacionadas com o saber, o poder e a identidade, ou seja, sinteticamente o conhecimento disciplinar, profissional, experiencial e curricular, a influência de grupos na formação e às modificações e adaptações que o currículo recebe nos diferentes espaços.

Assim sendo, acrescentar a Animação Turística - sustentada nos valores da Animação Sociocultural - no currículo de cursos de formação relacionados ao turismo não deve se restringir ao acréscimo de uma disciplina com tal nomenclatura. É imperativo que sua essência alcance os objetivos, justificativas e bases conceituais do curso como um todo. Porém, para tanto, seria preciso lidar não só com a relação de saber, mas também com a particularidade de cada localidade onde os cursos se encontram e com as variâncias de interesse cada grupo, uma vez que ainda é dada uma importância excessiva a temas econômicos no turismo. 


\section{Considerações Finais}

Este documento abordou nas partes iniciais aspectos gerais, porém significativos da Animação Sociocultural trabalhados por distintos autores da Europa e da América Latina.

Sabe-se que, devido a recente emergência dos estudos sobre essa área, ainda é preciso percorrer um longo caminho para levantar reflexões e estratégias que complementem a proposta da Animação Sociocultural. Assim, é imprescindível um engajamento de um maior número de estudiosos e interventores, pois parte da teoria sobre este instrumento ainda está em construção.

Pautando-se na característica multifacetada da Animação Sociocultural, torna-se importante fazer relações com outros tipos de campos que possuem certa proximidade com a essência do termo, como o turismo. Para tanto, lançou-se aqui um debate preliminar sobre as contribuições que a Animação Sociocultural poderia fornecer ao campo do turismo, especificamente no aspecto da Animação Turística.

Ao ampliar o olhar deste campo, as bases econômicas que tendem a imperar sobre ele poderiam ceder espaço para a construção de uma nova visão para os seus envolvidos. Sujeitos que foram apresentados em quatro categorias neste texto: os turistas, os autóctones ou moradores da cidade/localidade turística, o corpo docente dos cursos de turismo e os funcionários do setor, seja na esfera pública ou privada.

É preciso vislumbrar um processo diferente para o turismo, visto que o atual se mostra muitas vezes descompromissado com os anseios dos turistas e com os contextos locais. A Animação Turística, pautada nos conceitos da Animação Sociocultural, poderia auxiliar nessa mudança de perspectiva, indo de encontro às expectativas que vêm se configurando, como: a) o respeito aos autóctones, b) busca do turista por informações sobre as áreas a serem visitadas, c) conhecer o estilo de vida da população local, d) estudo da língua local por turistas estrangeiros, e) e a questão do querer "tocar", ou seja, buscar uma proximidade maior com as riquezas da localidade, materiais e imateriais.

Buscando desfechar momentaneamente esta discussão, a idéia de propor um estudo sobre Animação Turística não visa dividir o campo da Animação Sociocultural, fato que traria mais complicações do que contribuições. A pretensão é reforçar as suas bases ao trazer outros adeptos e outras fontes de reflexão, ao mesmo tempo em que a Animação Sociocultural ajudaria a ampliar as percepções da experiência turística por meio da Animação Turística. 
Como desfecho, fica a seguinte questão: que tipo de animação os envolvidos com a atividade turística deveriam trabalhar - uma voltada para as estratégias de cativação e de serviço complementar ou uma baseada no enriquecimento intercultural?

\section{Referências}

ALVES, Vânia de Fátima N. 2004. Cultura. In: GOMES, Christianne L. (Org.). Dicionário crítico do lazer. Belo Horizonte: Autêntica. p. 54-60.

ANDER-EGG, Ezequiel. 2006. La animación sociocultural en Iberoamérica ante el siglo XXI. In: VENTOSA, Victor Pérez (coord.). Perspectivas actuales de la animación sociocultural. Madrid: Editorial CCS. p. 17-29.

ARAÚJO, Marina. 2007. A educação pelo e para o turismo: uma perspectiva a partir da leitura da paisagem. In: SILVA, Jamerson, A. de A. da; SILVA, Katharine N. P. Recreação, Esporte e Lazer: espaço, tempo e atitude. Recife: Instituto Tempo Livre, p. 459-465.

BRASIL. Constituição: República Federativa do Brasil. 1988. Brasília: Senado Federal, Centro Gráfico.

BURNS, Peter M. 2002. Turismo e antropologia: uma introdução. Tradução de Dayse Batista. São Paulo: Chronos. Título original: Na Introduction to Tourism and Anthropology.

FRANÇA, Tereza. 2005. Lazer e Formação Profissional. Licere, v. 8, n. 1, p. 20-33.

GASTAL, Susana; MOECH, Marutschka W. 2007. Turismo, Políticas públicas e cidadania. São Paulo: Aleph.

GEERTZ, Clifford. 1979. Interpretação de culturas. Rio de Janeiro: Zahar.

GILLET, Jean C. 2006. A recreação e o lazer na França: Que perspectiva? In: MELO, Victor Andrade de; TAVARES, Carla. O exercício reflexivo do movimento. Rio de Janeiro: Shape. p. 112-128.

GOMES, Ana Maria R.; FARIA, Eliene L. 2005. Lazer e diversidade cultural. Brasília: SESI/DN.

HALL, Stuart. 1997. A centralidade da cultura: notas sobre as revoluções culturais de nosso tempo. Educação e Realidade.

HIGUCHI, Kazuko K. s/d. Entrando no jogo. TVE. Disponível em: <http://www.tvebrasil.com.br>. Acesso em: 08 abr 2003.

KRIPPENDORF, Jost. 2001. Sociologia do turismo: para uma nova compreensão do lazer e das viagens. São Paulo: Aleph.

LACERDA, Leonardo Lincoln Leite de. 2007. Lazer-turístico, em grandes centros urbanos, voltado para os próprios residentes: uma possibilidade? In: SILVA, Jamerson A. de A. da; SILVA, Katharine N. P. (Org.). Recreação, Esporte e Lazer: espaço, tempo e atitude. Recife: Instituto Tempo Livre.

LOPES, Marcelino de Sousa. 2007. A Animação Sociocultural em Portugal. Animador Sociocultural: Revista Iberoamericana, Salamanca, v. 1, n. 1, out-fev. 2007. Disponível em: $<\mathrm{http}: / / w w w . l a z e r . e e f d . u f r j . b r / a n i m a d o r s o c i o c u l t u r a l />$. Acesso em: 26 de jul, 2007.

MARCELLINO, Nelson C. 2000. O lazer na atualidade brasileira: perspectivas na formação/atuação profissional. Licere, v. 3, n. 1, p. 125-133.

MATIAS, Marlene. 2002. Turismo: formação e profissionalização (30 anos de história). Barueri: Manole.

MELO, Victor Andrade de. 2006. A Animação Cultural: conceitos e propostas. Campinas, SP: Papirus. 
PEREIRA, Carlos Augusto S. 2006. Apontamentos iniciais para um conceito de Animação Cultural. In: SEMINÁRIO “O LAZER EM DEBATE”, 7, Belo Horizonte. Coletânea... Belo Horizonte: Imprensa Universitária/CELAR/DEF/UFMG. p. 361-367.

RIBEIRO, Olívia C. F. 2002. A atuação do profissional do lazer nos hotéis: proporcionando o prazer ou a obrigação? Licere, v. 5, n. 1, p. 93-100.

; QUEIROZ, Emerson; SOUZA, Luciana M. de. 2004. Os hotéis de lazer no estado de São Paulo: um diagnóstico. Licere, v. 7, n. 1, p. 25-34.

SANTOS FILHO, João dos. 2005. Ontologia do turismo: estudos de suas causas primeiras. Caxias do Sul: Educs.

s/d. 27 de setembro: dia do Turismólogo - festejar ou organizar? Disponível em: $<$ http://www.revistaturismo.com.br/artigos/artigos.htm>. Acesso em: 03 ago 2006.

SEVERINO, Susana S.; SCHWEGLER, Fabiane W.; SILVA, Renata. 2006. Os impactos da atividade turística, estudo na Praia da Daniela. Caderno Virtual de Turismo, p. 51-58.

SILVA, Tomaz Tadeu da. 2005. Documentos de identidade: uma introdução às teorias do currículo. 2. ed. Belo Horizonte: Autêntica.

SOUZA E SILVA, António. 2008. O desenvolvimento local e a animação turística. In: PEREIRA, José D. L.; VIEITES, Manoel F.; LOPES, Marcelino de S. (coord.). A animação sociocultual e os desafios do século XXI. [Ponte de Lima]: Intervenção - Associação para Promoção e Divulgação Cultural, p. 69-91.

STOPPA, Edmur A.; ISAYAMA, Hélder F. 2001. Lazer, mercado de trabalho e atuação profissional. In: WERNECK, Christianne L. G.; STOPPA, Edmur A.; ISAYAMA, Hélder F. Lazer e Mercado. Campinas: Papirus.

TORRES, Zilah Barbosa. 2004. Animação turística. 3 ed. São Paulo: Rocca.

VENTOSA, Victor Pérez. 2007. La animación sociocultural en España: una perspectiva local. Animador Sociocultural: Revista Iberoamericana, Salamanca, v. 1, n. 1, out-fev. Disponível em: $<$ http://www.lazer.eefd.ufrj.br/animadorsociocultural/>. Acesso em: 26 de jul 2007.

. 2007 ¿De que hablamos cuando hablamos de animación sociocultural? Animador Sociocultural: Revista Iberoamericana, Salamanca, v. 1, n. 2, mai-set. Disponível em: $<$ http://www.lazer.eefd.ufrj.br/animadorsociocultural/>. Acesso em: 26 de jul 2007.

\section{Recebido em: 14/10/2008 (1 ${ }^{\text {a }}$ versão) $13 / 04 / 2009$ ( $2^{\mathrm{a}}$ versão) \\ Aprovado em: 15/05/2009}

